\title{
POSSÍVEIS CONTRIBUIÇÕES PARA OS ESTUDOS DO LAZER, A PARTIR DA TEORIA DO PROCESSO CIVILIZADOR
}

Recebido em: 11/07/2011

Aceito em: 03/02/2012

\author{
Renata Morais do Nascimento ${ }^{1}$ \\ Nelson Carvalho Marcellino ${ }^{2}$ \\ Universidade Metodista de Piracicaba - Unimep \\ Piracicaba - SP - Brasil
}

RESUMO: Este artigo de revisão procura analisar algumas contribuições para os estudos do lazer a partir da "teoria do processo civilizador", de Norbert Elias, consubstanciadas em A busca da excitação: desporto e lazer no processo civilizacional, de Elias e Eric Dunning. São destacados os seguintes pontos: crítica à tradicional análise do lazer como prática presa à dicotomia "lazer x trabalho"; entendimento do lazer como uma busca por excitação e prazer que, por conta do controle exercido sobre os impulsos das pessoas, não podem ser manifestados na vida cotidiana; distinção entre os conceitos de "tempo livre" e "lazer". As contribuições são importantes para quem se propõe a estudar questões relacionadas ao lazer.

PALAVRAS CHAVE: Atividades de Lazer. Sociologia. História.

\section{TENTATIVE CONTRIBUTIONS TO THE STUDY OF LEISURE BASED ON THE THEORY OF THE CIVILIZING PROCESS}

ABSTRACT: The present paper seeks to analyze some contributions to the studies on leisure based on Norbert Elias" "theory of the civilizing process", consolidated in Elias and Eric Dunning's Sport and leisure in the civilizing process. Emphasis is given to the following points: critique of the traditional analysis of leisure as a practice bound to the "leisure x work" dichotomy; the understanding of leisure as a quest for excitement and pleasure, which cannot be manifested in daily life due to the control imposed on people's impulses; the distinction between the concepts of "free time" and "leisure". These contributions are basic for those who study leisure-related issues.

KEYWORDS: Leisure Activities. Sociology. History.

1 Licenciada em História pela Unimep, bolsista de iniciação científica do CNPq, membro do Grupo de Pesquisa em Lazer (GPL).

2 Docente do mestrado e graduação em Educação Física da Unimep; coordenador do Núcleo da Rede Cedes, líder do Grupo de Pesquisa em Lazer (GPL), Unimep; membro do ORICOLÉ, Laboratório de pesquisa sobre formação e atuação profissional, UFMG, e pesquisador do CNPq. 


\section{Introdução}

Procuramos analisar, aqui, algumas possíveis contribuições para os estudos do lazer a partir da "teoria do processo civilizador", exposta por Norbert Elias na obra $O$ processo civilizador (ELIAS, 1990 e 1993), consubstanciadas em A busca da excitação: desporto e lazer no processo civilizacional (ELIAS; DUNNING, 1992).

Este último livro foi publicado originalmente em 1985, pelos sociólogos Norbert Elias e Eric Dunning, com participação de Patrick Murphy e John Willians. Trata-se de uma coleção de artigos que abordam questões relacionadas às atividades de lazer, sendo que há grande enfoque ao esporte - sobretudo o futebol e o rugby. Os objetivos dos autores são claros: buscam destacar a importância e o interesse dessas questões para a investigação sociológica, o que era pouco corrente no período, e lançam as bases para uma possível teoria sociológica do lazer e do esporte. Os autores têm como referencial a teoria do processo civilizador, de Elias, e fogem de divisões das sociedades em "categorias", como feito por especialistas, integrando, assim, o tema dos estudos a uma análise global da sociedade. É importante destacar que os trabalhos têm o objetivo de traçar uma nova teoria e modo de investigação sociológica geral, e não apenas do lazer.

Em sua introdução, Eric Dunning afirma que quando a Sociologia se estabeleceu como disciplina, seus fundadores não consideravam o desporto um problema social sério, nem fundamental. Assim, apesar de entenderem a Sociologia como ciência que trata das sociedades em todas as suas dimensões, os sociólogos limitavam seus trabalhos a estudos de paradigmas dominantes, aderindo a um pequeno conjunto de atividades às quais o desporto não seria importante. Poucos conseguiam afastar-se suficientemente dos "valores dominantes" e "formas de pensamento" característicos das sociedades ocidentais e perceber que o desporto tem um significado social geralmente ignorado nas 
teorias por ser considerado por muitos algo negativo, vulgar, porque associado ao lazer e ao prazer.

[...] a sociologia orientou-se para o campo restrito dos aspectos "sério" e "racional" da vida, o que teve como efeito que o divertimento, o prazer, o jogo, as emoções e as tendências "irracionais" e "inconscientes" do homem e da mulher tivessem merecido escassa atenção no âmbito da teoria e da investigação sociológicas. (ELIAS; DUNNING, 1992, p. 16).

Ao criticar severamente o desprezo da maior parte dos estudiosos da Sociologia, Elias e Dunning defendem que o lazer possui um importante significado social que precisa de investigação e teorização sociológicas. E é a isso que pretendem voltar-se. Para tanto, utilizam-se da teoria sociológica de Elias sobre o processo de civilização das sociedades.

A "teoria do processo civilizador" de Elias é amplamente explorada na obra " $O$ processo civilizador", de 1939. Segundo Elias, o aumento de centralização política que torna decisivo o direito de utilização de força física e cobrança de impostos por parte do Estado e a intensa mudança no equilíbrio de poderes entre as classes sociais e demais grupos são pontos importantes para o processo de refinamento de condutas humanas e padrões sociais de comportamento em todas as esferas da vida, que começa a ocorrer desde a chamada Idade Média. A partir de então surge uma configuração social na qual aumenta o controle dos comportamentos e "pulsões" por meio de discursos, normas, poderes institucionalizados e censura para que as pessoas exerçam o autocontrole da agressão, sexualidade, relações sociais de todo tipo, emoções, costumes, enfim, comportamento. O discurso dos autores acerca do lazer é em grande medida pautada nesse autocontrole do comportamento dos indivíduos que, segundo Dunning, "é uma teoria que permite avaliar o significado social do desporto" (ELIAS; DUNNING, 1992, p.19). 
É nos dois primeiros capítulos da obra que se encontra a argumentação acerca da teoria que os autores buscam elaborar sobre o lazer e seu significado na vida das pessoas nas sociedades industriais. Visto que o objetivo do presente trabalho é justamente buscar a possibilidade e relevância na utilização de Elias e Dunning como referencial teórico para estudos acerca do lazer, o foco da análise estará nos dois primeiros capítulos, que abordam essa questão.

\section{Limitações no entendimento e as abordagens "tradicionais" sobre tempo livre e lazer}

Elias e Dunning discutem o que consideram uma limitação no entendimento do lazer enquanto apêndice do trabalho, tão comum em abordagens sociológicas sobre o lazer. Questiona qual seria a resposta à função do lazer como acessório do trabalho, visto como um meio para atingir o fim de aliviar tensões e melhorar a capacidade das pessoas de retornar ao trabalhar. Elaboram, então, um breve resumo do que consideram alguns pontos críticos dessas limitações que observam na abordagem tradicional do lazer estritamente ligado e condicionado ao trabalho.

Segundo entendem, a abordagem das questões relacionadas ao lazer, entendidas como estritamente relacionadas ao trabalho, possui certa consistência em virtude de um sistema de valores segundo o qual a essência das coisas boas e válidas da vida está ligada ao trabalho realizado e, durante as horas em que não é preciso trabalhar, as pessoas realizam atividades de menor ou nenhuma importância. Nisso o lazer serviria como forma de atenuar o cansaço e a tensão das horas de trabalho.

Para os autores, a idéia de que as atividades de lazer são como auxiliares do trabalho exige crítica. Em seu entender, esse tipo de abordagem não é suficiente. Questionam, por exemplo, quais seriam os esforços de trabalho aos quais as pessoas buscariam alívio nas atividades de lazer. Se for fadiga, afirmam, melhor seria dormir 
que ir ao teatro ou futebol. O desconhecimento de quais são essas fadigas para as quais as pessoas buscariam alívio no lazer, argumentam, dificulta a definição da forma como as atividades de lazer proporcionam o relaxamento esperado.

Existe uma boa dose de evidência sugerindo que as estruturas e funções das de lazer não podem ser compreendidas se não se considerarem como um fenômeno social por direito próprio, independente de actividades de não lazer, mas, do ponto de vista funcional, de valor não inferior, não subordinadas a elas. (ELIAS; DUNNING, 1992, p. 141).

Outro ponto destacado é a abordagem das atividades de lazer como forma de permitir que as pessoas trabalhem melhor, ou a tese de que não existe lazer fora da perspectiva do trabalho, que provavelmente seriam sintomas de um sistema de julgamentos e valores tradicionais que relaciona o prazer à perda de tempo; segundo esse tipo de julgamento, o lazer não seria importante por não fazer parte das "coisas sérias da vida".

No terceiro ponto, os autores afirmam que atividades de lazer explicadas a partir de uma função - a de proporcionar relaxamento de tensões e fadigas, tidos como algo do qual as pessoas querem se livrar - é um erro, já que se as tensões são meras perturbações das quais as pessoas querem se livrar, por que elas voltam a procurar tensão no tempo de lazer?

Em vez de condenar as tensões como algo que prejudica, não se deveria antes as necessidades que as pessoas relevam por uma dose de tensão, enfim, como um ingrediente normal nas suas vidas? Não se deveria antes tentar distinguir com maior clareza entre tensões que são sentidas como agradáveis e tensões que são sentidas como desagradáveis? (ELIAS; DUNNING, 1992, p. 143).

O quarto ponto é uma crítica à falta da necessária distinção na utilização dos termos "lazer" e "tempo livre" como conceitos. "Sem uma classificação, como tem sucedido até agora, continua obscuro o lugar do lazer no tempo livre das pessoas e a 
relação entre os numerosos tipos de actividades de tempo livre" (ELIAS; DUNNING, 1992, p. 143).

Por conta dos itens acima, que os autores chamam de "deficiências", teriam surgido consequências ruins nos estudos sobre o lazer. Dois exemplos são: a) as investigações concentradas em certas áreas do lazer, em detrimento de outras que raramente são temas de investigação; b) a falta de uma teoria sobre o lazer capaz de investigar seus problemas específicos, o que todas as atividades têm em comum e o que as distingue entre si e de outras atividades humanas. Enfim, os autores criticam a inexistência de uma teoria do lazer e afirmam que "este estudo tenciona ser um passo nessa direção. É um movimento no sentido de uma teoria do lazer unificada" (ELIAS; DUNNING, 1992, p. 144).

\section{Distinção entre atividades realizadas no tempo livre}

Para Elias e Dunning, as observações críticas acima exigem uma nova forma de pensar o tempo livre, para depois ser possível analisar as diferenças e relações entre as atividades realizadas, entre as quais está o lazer. Assim, elaboram um quadro que tem por objetivo uma precisa síntese sobre as relações e diferenças entre as atividades praticadas no chamado tempo livre.

\footnotetext{
Mostra, em síntese, que as actividades de lazer são apenas um tipo entre outros. mesmo tempo, indica a relação entre o lazer e outras atividades de tempo livre. Como pode ver-se, a distinção é bastante óbvia: todas as actividades de lazer são actividades de tempo livre, mas nem todas as de tempo livre são de lazer. (ELIAS; DUNNING, 1992, p. 145).
}

Essa análise é chamada pelos autores de "espectro do tempo livre", uma forma de distinguir as atividades realizadas nesse período. Assim, o tempo livre é "dividido" de acordo com as características das atividades praticadas. 
O espectro do tempo livre é um quadro de classificação que indica os principais tipos de actividades de tempo livre nas nossas sociedades. Com o seu auxílio, podem observar-se rapidamente factos que estão, com frequiência, obscurecidos pela tendência para equacionar o tempo livre enquanto actividades de lazer: algumas actividades de tempo livre têm o caráter de trabalho, ainda que constituam um tipo que se pode distinguir do trabalho profissional; algumas das actividades de tempo livre, mas de modo algum todas, são voluntárias; nem todas são agradáveis e algumas são altamente rotineiras. As características especiais das actividades de lazer só podem ser compreendidas se forem consideradas, não apenas em relação ao trabalho profissional mas, também, em relação às várias actividades de não lazer, no quadro de tempo livre. Desta maneira, o espectro do tempo livre contribui para dar maior precisão ao problema do lazer. (ELIAS; DUNNING, 1992, p. 149).

A seguir, uma síntese do "espectro do tempo livre" (ELIAS; DUNNING,

1992, p. 146-148), com algumas considerações retiradas da seção "Actividades de tempo livre: classificação preliminar”, do capítulo “A busca da excitação no lazer”, que define "cinco esferas diferentes do tempo livre" (ELIAS; DUNNING, 1992, p. 107110):

1. Rotinas do tempo livre: atividades relacionadas à provisão rotineira de necessidades biológicas, da casa e da família. Algumas dessas atividades tratam de organização administrativa, outras de necessidades. Ambas dificilmente podem ser chamadas de lazer, mas algumas que tratam de suprir necessidades podem produzir satisfações quando praticadas de maneira não rotineira.

2. Atividades direcionadas à formação, auto-satisfação e autodesenvolvimento: trabalho voluntário, passatempos relacionados a estudos e estudos especializados sem motivos profissionais, passatempo com trabalhos amadores, atividades religiosas, busca de conhecimento e informações sobre questões "sérias".

3. Atividades de lazer, que podem ser divididas em diferentes grupos de acordo com suas características: 
a) atividades sociáveis: reuniões formais ou informais coletivas que visam à sociabilidade. Por exemplo: festas, encontros, bate-papo.

b) atividades de jogo ou miméticas: são atividades que representam uma enorme diversidade. Nesta categoria estão atividades de lazer como cinema, concerto musical, dança, teatro, corridas, caça, pesca, jogos de carta, apostas, televisão, rádio, prática de esportes. Nestas atividades, o indivíduo pode participar tanto como ator quanto como espectador - mas se for atividade com que o indivíduo "ganha a vida", ela deixa de ser lazer para tornar-se trabalho. São atividades que geralmente envolvem uma destruição de rotinas e alívio de restrições por meio do movimento corporal. $\mathrm{O}$ aspecto mimético no sentido literal quer dizer “imitativo", mas é utilizado para referir-se não a representações ou imitações da "vida real", mas a atividades que produzem emoções e excitações que, embora relacionadas ao imaginário, possuem semelhanças com as emoções sentidas na “vida real”. As atividades miméticas são, em grande medida, características pela explosão pública de fortes emoções.

c) atividades de lazer com característica de busca do agradável que quebre a rotina. Exemplo: viagens, comer fora de casa, relações de amor que destroem a rotina, cuidados com o corpo como banho de sol ou passeios.

\section{Lazer como fuga da rotina e busca de excitação}

As características que distinguem as atividades do tempo livre estão mencionadas no "espectro do tempo livre". Falta tratar dos pontos comuns, como Elias e Dunning se referiram. Argumentam eles que numa sociedade em que a maior parte das atividades humanas está submetida à rotina, as atividades de lazer proporcionam, 
mesmo com limites, oportunidades para experiências emocionais e excitações agradáveis excluídas da vida rotineira. Nas atividades de lazer, as restrições rotineiras de emoções podem ser reduzidas de forma pública com aprovação social, podendo, assim, um indivíduo ter oportunidades de passar por emoções agradáveis. Nas atividades de lazer, diferentemente da maior parte das outras atividades, a satisfação pessoal, individual, pode ser prioridade.

Segundo os autores, nenhum outro tipo de atividade pública oferece campo tão vasto de divertimento individual intenso e espontâneo quanto o lazer. Isso porque são as ocupações de lazer que oferecem maiores oportunidades de momentos agradáveis, estímulo de emoções e excitação que podem ocorrer em público e serem partilhadas por outros com a aprovação social.

Um ponto importante das considerações que fazem sobre essas características das atividades de lazer é que, segundo afirmam, essas emoções agradáveis experimentadas em atividades de lazer estão, muitas vezes, relacionadas a formas específicas de "tensão aprazível”, tensão que diz respeito ao risco que seria essencial em diversas atividades de lazer, constituindo um elemento de prazer.

\footnotetext{
No conjunto das actividades de lazer, todas integram um tipo peculiar de risco. São capazes de desafiar a rigorosa ordem da vida rotineira das pessoas sem colocar em perigo os meios de subsistência ou o seu estatuto. Permitem às pessoas tornar mais fáceis ou ridicularizar as normas da sua vida de não lazer, e todos o fazem sem ofender a consciência ou a sociedade. (ELIAS; DUNNING, 1992, p. 151).
}

O que as pessoas procuram no lazer não seria o alívio de tensões, mas a vivência de um tipo de tensão que evitam na vida cotidiana. Segundo Elias e Dunning, os sentimentos antagônicos de medo e prazer não são apenas opostos, mas inseparáveis na satisfação obtida pelo lazer. O fundamental da busca do prazer por meio do lazer seria uma "agradável" fusão entre tensão e excitação. Seria este o motivo principal para que 
as formas de excitação desempenhem papel central em atividades de lazer, possibilitando compreender o lazer como um destruidor da rotina. A rotina, afirmam, possui um alto nível de segurança e não pode ser afastada, mesmo que de forma temporária, sem que o indivíduo se exponha a um nível de insegurança.

Se perguntarmos de que modo é que se animam os sentimentos, como é que a excitação é favorecida pelas atividades de lazer, descobrimos que isso é dinamizado, habitualmente, por meio da criação de tensões. Perigo imaginário, medo ou prazer mimético, tristeza e alegria são produzidos e possivelmente resolvidos no quadro dos divertimentos. Diferentes estados de espíritos são evocados e talvez colocados em contraste, como a angústia e a exaltação, a agitação e a paz de espírito. Deste modo, os sentimentos dinamizados numa situação imaginária de uma actividade humana de lazer têm afinidades com os que são desencadeados em situações reais da vida - é isso que a expressão "mimética" indica - , mas o último está associado aos riscos e perigos sem fim da frágil vida humana, enquanto o primeiro sustenta, momentaneamente, o fardo de riscos e de ameaças, grandes e pequenas, que rodeia a existência humana. (ELIAS; DUNNING, 1992, p. 71).

Afirmam os autores que a excitação que as pessoas procuram no lazer é agradável, com características específicas, ao mesmo tempo em que revela semelhanças com o que as pessoas vivenciam em situações críticas sérias.

Comparadas às sociedades menos desenvolvidas, os constatam, as sociedades industriais mais avançadas possuem menos situações críticas produtoras de excitação nos indivíduos, em virtude do exagerado aumento do controle social e do autodomínio da excitação. Assim, explosões incontroláveis de paixão e excitação coletiva são cada vez menos frequentes, sendo que manifestações de extrema excitação podem resultar em punição por meio de prisão ou internação em hospitais. Mesmo as situações de grande crise na vida privada, que causam sentimentos fortes, geralmente ficam escondidas na intimidade. Rituais e cerimônias não provocam mais a excitação de estágios anteriores das sociedades, ou de sociedades "mais simples".

Enorme medo e profunda alegria, acentuado ódio e extremo amor, têm de apresentar-se sob outra aparência. Só as crianças saltam e dançam com excitação, apenas estas não são censuradas de imediato como descontroladas 
ou anormais, se choram e soluçam publicamente, em lágrimas desencadeadas pelos seus sofrimentos súbitos, se entram em pânico num medo selvagem, ou se cerram os punhos com firmeza e batem ou mordem o odiado inimigo, num total abandono quando se excitam. Ver homens e mulheres adultos agitarem-se em lágrimas e abandonarem-se às suas amargas tristezas em público, ou entrarem em pânico dominados por um medo selvagem, ou baterem-se uns aos outros de forma selvagem debaixo do impacto da sua excitação violenta, deixou de ser encarado como normal. Habitualmente é motivo de embaraço para quem assiste e, com freqüência, motivo de vergonha ou arrependimento para aqueles que se permitiram ser dominados pela excitação. Para serem considerados normais, espera-se que os adultos vivendo nas nossas sociedades controlem, a tempo, a sua excitação. Em geral, aprendem a não se expor demasiado. Com grande frequiência já não são capazes de revelar mesmo nada de si próprios. O controlo que exercem sobre si tornou-se, de certo modo, automático. [...] Tornou-se um aspecto da estrutura profunda da sua personalidade. (ELIAS; DUNNING, 1992, p. 103).

Nas sociedades industriais avançadas, afirmam os autores, é nas atividades de lazer que comportamentos públicos de manifestação da excitação controlada são permitidos. Porém, ressaltam, “as atividades de lazer enquanto área social de libertação das restrições do não lazer podem encontrar-se nas sociedades em todos os estágios do desenvolvimento" (ELIAS; DUNNING, 1992, p. 104). Dessa forma, os festivais dos antigos gregos e o carnaval medieval teriam funções semelhantes às das atividades de lazer atuais. Nessas sociedades com alto nível de civilização, há forte necessidade de sublimação devido ao, também alto, grau de restrições na vida cotidiana. O lazer cumpre com o papel de trazer essa sublimação ao indivíduo, porém as atividades devem conformar-se à sensibilidade em relação à violência física, característica dessas sociedades, ou seja, mesmo o lazer possui regras para conter os exageros de excitação, impulsos e violência.

A variedade das actividades de lazer nas sociedades mais diferenciadas é muito grande, as diferenças entre elas são acentuadas. Além disso, a maioria possui, em comum, características estruturais básicas. E estes traços comuns apontam para a função que preenchem como actividades de lazer em sociedades de um tipo de diferenciação elevado e complexo. Enquanto, nestas sociedades, as rotinas públicas ou privadas da vida exigem que as pessoas mantenham um perfeito domínio sobre os seus estados de espírito e sobre os seus impulsos, afectos e emoções, as ocupações de lazer e de algumas formas reminiscentes da sua realidade exterior autorizam-nas, de um modo geral, a fluir mais livremente num quadro imaginário 
especialmente criado por estas actividades. Enquanto, no caso das últimas, o conjunto de oportunidades de manifestações de sentimentos é pouco claro, ou confinado a sectores especiais, as actividades de lazer destinam-se a apelar directamente para os sentimentos das pessoas e animá-las, ainda que segundo maneiras e graus variados. Enquanto a excitação é bastante reprimida na ocupação daquilo que se encara habitualmente como as actividades sérias da vida - excepto a excitação sexual, que está mais estritamente confinada à privacidade - muitas ocupações de lazer fornecem um quadro imaginário que se destina a autorizar o excitamento, ao representar, de alguma forma, o que tem origem em muitas situações da vida real, embora sem os seus perigos e riscos. Filmes, danças, pinturas, jogos de cartas, corridas de cavalos, óperas, histórias policiais e jogos de futebol estas e muitas outras actividades de lazer pertencem a essa categoria (ELIAS; DUNNING, 1992, p. 71).

\section{"Elementos de lazer"}

Segundo Elias e Dunning, ao olharmos para o quadro "espectro do tempo livre", notaremos que não há nenhuma atividade de lazer que não possua os elementos de sociabilidade, mobilidade e imaginação, todos elementos que podem ser eficazes como meio de atenuar controles exercidos fora do lazer. Para explicar as funções desses três “elementos de lazer", são discutidas as duas esferas principais do lazer nas sociedades atuais: "sociabilidade" e "mimética".

Sociabilidade: Para os autores, a sociabilidade é um elemento básico do lazer e desempenha um papel na maioria das atividades. O estar acompanhado para exercer algo sem qualquer obrigação tem como função primária o prazer da sociabilidade.

\footnotetext{
Neste caso, em contraste com as instituições miméticas de lazer, as pessoas reúnem-se sem possuírem necessariamente qualquer competência técnica especializada, sem "actuação" para os outros ou para si próprias (embora isso possa acontecer acidentalmente), só para desfrutarem a companhia um dos outros, para terem prazer, isto é, um nível mais elevado de calor emocional, de integração social e de estimulação através da presença de outros - uma estimulação divertida, sem obrigações sérias e os riscos inerentes a elas - do que aquele que é possível experimentar em qualquer outra esfera da vida. (ELIAS; DUNNING, 1992, p. 180-181).
} 
A sociabilidade no lazer, para Elias e Dunning, opõe-se às características das sociedades industriais em que a rotina dominante exige uma forma de contato impessoal entre as pessoas, formando, assim, barreiras emocionais construídas por meio de restrições. A existência do lazer como forma de sociabilidade mostra a necessidade de enfraquecer as barreiras construídas nos contatos humanos.

Já as atividades miméticas têm distinções bastante claras da sociabilidade como lazer. O termo "mimético" é utilizado para designar diversas atividades de lazer que possuem uma característica estrutural em comum:

[...] despertam emoções de um tipo específico, que estão intimamente relacionadas de uma forma específica, diferente, com aquelas que as pessoas experimentam no decurso da sua vida ordinária de não lazer. No contexto dos factos miméticos, as pessoas podem experimentar e, em alguns casos, representar medo e riso, ansiedade e amor, simpatia e antipatia, amizade e ódio e muitas outras emoções e sentimentos que também podem experimentar na sua vida de não lazer. Mas no contexto mimético todos os sentimentos e, no caso de isso suceder, os actos dominados pelas emoções com eles relacionados transpõem-se. Perdem o seu ferrão. Mesmo o medo, o horror, o ódio e outros sentimentos que estão longe de serem agradáveis, e as acções correspondentes no quadro mimético, associam-se em maior ou menor dimensão a sentimentos de prazer [...]. No contexto mimético, o comportamento emocional e as experiências da vida ordinária adquirem uma tonalidade diferente. (ELIAS; DUNNING, 1992, p. 183-184).

Dessa forma, o que sustentaria as atividades miméticas de lazer é à busca de intensa excitação que, fora desse contexto, costuma ter suas manifestações controladas de forma dura. No contexto mimético a pessoa pode expressar, mesmo que de forma controlada por regras, sentimentos que, de outro modo, não seriam possíveis numa sociedade que impõe um estilo de vida no qual a rotina é destituída de quase toda emoção.

O que Elias e Dunning concluem é que todos os “elementos de lazer" possuem função de "antídotos para as rotinas da vida" (ELIAS; DUNNING, 1992, p. 184), por 
meio da busca de prazeres e excitações que, mesmo controlados por regras, as pessoas não podem manifestar em outros momentos.

\section{Considerações finais}

É interessante destacar a importância dos capítulos “A busca da excitação no lazer" e "O lazer no espectro do tempo livre" como textos que contribuem como embasamento aos estudos do lazer, por diferentes aspectos. Nesses textos, Elias e Dunning objetivam destacar o lazer como tema importante e interessante para o estudo sociológico, bem como lançar bases de uma possível teoria do lazer. De forma consistente, os autores levantam teses sobre o significado do lazer para as sociedades, sobretudo as atuais.

Ponto a destacar sobre os textos analisados é que os autores fazem uma crítica à tradicional análise do lazer como prática presa à dicotomia "lazer x trabalho". Não consideram que o lazer e os objetivos de sua prática sejam totalmente determinados pelo trabalho; dessa forma, defendem que o lazer só pode ser compreendido se analisado a partir da rotina dos indivíduos, não somente em relação ao trabalho, mas também em outras atividades do tempo livre.

Outra questão importante é que Elias e Dunning não compreendem as tensões como algo do qual as pessoas fogem em suas práticas de lazer. Pelo contrário, entendem o lazer como uma busca por excitação e prazer que, por conta do controle exercido sobre os impulsos das pessoas, não podem ser manifestados na vida cotidiana. Assim, um tipo de tensão agradável tem papel importante como quebra da rotina por meio de um perigo imaginário e provisório. 
Além disso, a distinção entre os conceitos de "tempo livre" e "lazer" e a análise das diferenças e semelhanças entre diversas atividades de lazer, que os autores também exploram de forma consistente, são de fundamental importância para quem se propõe a estudar questões relacionadas ao lazer.

\section{REFERÊNCIAS}

ELIAS, N. O processo civilizador: uma história dos costumes. Rio de Janeiro: Jorge Zahar Editor, 1990. v. 1.

O processo civilizador: formação do estado e civilização. Rio de Janeiro: Jorge Zahar Editor. 1993. v. 2.

ELIAS, N.; DUNNING, E. A busca da excitação. Lisboa: Difel, 1992.

\section{Endereço dos Autores:}

Nelson Carvalho Marcellino

Rua 14 de dezembro, 428 - apto. 41

Campinas - SP - 13015-130

Endereço Eletrônico: ncmarcel@unimep.br. 